\title{
Lack of Direct Action of Atriopeptidase Inhibitor on Cellular pH Regulation in Rabbit S2 Proximal Straight Tubules
}

\author{
Nobuyuki Takahashi, Yoshiaki Kondo*, Kei Kudo, \\ Yutaka Igarashi*, Osamu Ito and KeIshi Abe† \\ Department of Clinical Biology and Hormonal Regulation, \\ *Department of Pediatrics, and $\dagger$ the Second Department of \\ Internal Medicine, Tohoku University School of Medicine, \\ Sendai 980
}

Takahashi, N., Kondo, Y., Kudo, K., Igarashi, Y., Ito, O. and Abe, K. Lack of Direct Action of Atriopeptidase Inhibitor on Cellular $p H$ Regulation in Rabbit S2 Proximal Straight Tubules. Tohoku J. Exp. Med., 1993, 169 (4), 261270 - While the in vivo diuretic and antihypertensive effects of the newlydeveloped drug Candoxatril (UK-79300), a prodrug of a selective atriopeptidase inhibitor UK-73967 (API) are well established, the mechanism of its diuretic action is not yet fully understood due to the lack of information about its direct effects on proximal tubules. To elucidate whether this atriopeptidase inhibitor has any direct effects on proximal tubules, we examined the effect of API on intracellular $\mathrm{pH}(\mathrm{pHi})$ of the in vitro microperfused proximal S2 segment of rabbit kidney, using the $\mathrm{pH}$-sensitive fluorescent dye, $\left(2^{\prime}, 7^{\prime}\right)$-bis(carboxyethyl)-(5,6)carboxyfluorescein (BCECF). In the steady-state condition, $\mathrm{pHi}$ was $7.13 \pm 0.02$ $(n=19)$. Atriopeptidase inhibitor (API) at $100 \mu \mathrm{M}$ added to the bath changed pHi by only $0.02 \pm 0.07$ unit $(n=7, p>0.05)$ in $10 \mathrm{~min}$. The same concentration of API in the lumen changed pHi by $0.03 \pm 0.02$ unit $(n=6, p>0.05)$. To test whether the synergistic effects of API on the luminal and basolateral transport systems prevented the apparent change in $\mathrm{pHi}$, we also examined the effect of API in the presence of amiloride in the lumen. The inhibition of $\mathrm{Na}^{+} / \mathrm{H}^{+}$antiporter by the addition of $1 \mathrm{mM}$ of amiloride to the lumen caused no change in $\mathrm{pHi}$ response to basolateral API application. API was without effect on pHi also in the presence of atrial natriuretic polypeptide (ANP). These results suggest that API per se has no significant effect on the process of proximal acidification over a short time period. U UK-79300; atrial natriuretic polypeptide; kidney; proximal tubule

Since De Bold first described potent natriuretic and diuretic effects of the atrial extract of rat heart in 1981 (De Bold et al. 1981), there have been many studies regarding the atrial natriuretic factor (ANF). In 1984, several groups of

Received February 8, 1993; revision accepted for publication March 4, 1993.

Mailing address: N. Takahashi, M.D. Department of Clinical Biology and Hormonal Regulation, Tohoku University School of Medicine, 1-1 Seiryo-machi, Aoba-ku, Sendai 980, Japan. 
the investigators purified the peptides of the atrial natriuretic factor and sequenced its cDNA (Flynn et al. 1983; Atlas et al. 1984; Kangawa et al. 1984; Maki et al. 1984; Yamanaka et al. 1984). These purified peptides were named atrial natriuretic polypeptide (ANP), atriopeptin, atrial natriuretic factor, etc. Physiological studies of in vivo clearance (Gerves and Vollmar 1990), renal regional blood flow (Borenstein et al. 1983; Camargo et al. 1984), etc. have demonstrated the effect of ANF mainly on the renal vasculature. These studies suggested initially that the primary natriuretic effect involves an increase in the renal medullary blood flow (Borenstein et al. 1983; Takezawa et al. 1987). This phenomenon was called 'medullary washout'. On the other hand, the direct renal tubular effect was also examined by means of the in vitro microperfusion technique. Kondo et al. first examined the effects of human atrial natriuretic polypeptide on the loop segments (Kondo et al. 1986), and found no effect. This result supported the idea that the medullary washout is primarily a vascular phenomenon. On the other hand, recent studies have revealed that the natriuretic factor also acts directly on the renal proximal tubule (Harris et al. 1987; Garvin 1989; Winaver et al. 1990) and collecting duct system (Dillingham and Anderson 1986; Zeidel et al. 1986, 1988; Nonoguchi et al. 1988, 1989; Rocha and Kudo 1990). Although a direct effect on the papillary collecting duct was not confirmed, it is now generally accepted that a portion of the natriuretic action of ANF is its renal tubular effect.

Studies regarding the metabolism of ANF have established that it is catabolized mainly by atriopeptidase, which is present in the brush border membrane of the renal proximal tubule (Olins et al. 1987). Recently, a new substance that inhibits the function of atriopeptidase at a very low dose was discovered. This atriopeptidase inhibitor (API), named Candoxatril (UK-79300), clearly raised the serum level of ANF in vivo (Northridge et al. 1989). Although the primary mechanism of natriuresis and diuresis by Candoxatril seems to be an increase in the serum level of ANF (Northridge et al. 1989; Richard et al. 1990), it is still unclear whether API directly affects the proximal tubule.

To elucidate the mechanism of the natriuretic effect of API, we examined the direct effect of API on the proximal tubular acidification capacity by in vitro microperfusion of the rabbit $\mathrm{S} 2$ proximal straight tubule and measurement of its intracellular $\mathrm{pH}(\mathrm{pHi})$. Our results suggest that API has no direct effect on the regulation of cellular $\mathrm{pH}$ in the rabbit proximal $\mathrm{S} 2$ straight tubule over a short time period.

\section{Materials and Methods}

Female Japanese white rabbits weighing $1.5-2.0 \mathrm{~kg}$ were anesthetized with pentobarbital sodium (50 mg/kg i.v.). After 5-10 min, kidneys were removed and cut into coronal slices 3-4 $\mathrm{mm}$ thick and placed in a chilled dissection medium containing (in mmol/liter); $14 \mathrm{KCl}, 44 \mathrm{~K}_{2} \mathrm{HPO}_{4}, 14 \mathrm{KH}_{2} \mathrm{PO}_{4}, 9 \mathrm{NaHCO}_{3}$, and 160 sucrose. With fine forceps, frag- 
ments of the S2 segment were microdissected from the middle part of a medullary ray in the renal cortex under a stereoscopic microscope. With a glass pipette, the tubules were then transferred to a perfusion chamber mounted on the stage of an inverted microscope. The fluid in the perfusion chamber was continuously exchanged at about $5-10 \mathrm{ml} / \mathrm{min}$. Isolated fragments of S2 straight tubules were microperfused in vitro by the method of Burg et al. (1966) with minor modifications as described previously (Kondo and Froemter 1987). Tubules were preincubated in the control solution for 15-25 min until autofluorescence came to a steady state. Control solution was first equilibrated with $5 \% \mathrm{CO}_{2}-95 \% \mathrm{O}_{2}$ gas at room temperature for more than thirty minutes and then maintained at $37^{\circ} \mathrm{C}$ by means of a conventional thermistor-regulated heating system with continuous bubbling of solutions with $5 \% \mathrm{CO}_{2}-95 \% \mathrm{O}_{2}$. The composition of the control solution was (in mmol/liter) 120 $\mathrm{NaCl}, 3 \mathrm{KCl}, 2 \mathrm{KH}_{2} \mathrm{PO}_{4}, 1.5 \mathrm{CaCl}_{2}, 1.0 \mathrm{MgCl}_{2}, 5.5$ glucose, 5 L-alanine, and $25 \mathrm{NaHCO}_{3}$.

After the equilibration period, tubules were loaded with acetoxymethyl ester of the $\mathrm{pH}$-sensitive dye, $(2,7)$-bis-(carboxyethyl)-(5,6)-carboxyfluorescein (BCECF/AM), from the lumen at a concentration of $10^{-6} \mathrm{~mol} / \mathrm{liter}$ for 5 to $8 \mathrm{~min}$. More than 5 min after BCECF/AM was washed out of the lumen, measurements were started on an inverted microscope equipped with the OSP-3 system (Olympus, Tokyo) and a 20x objective. The dye trapped in the tubule cells was excited alternately at 490 and $440 \mathrm{~nm}$ and the emission light at $530 \mathrm{~nm}$ was measured by a photomultiplier. After correcting for background measurement, the fluorescence excitation ratio ( F490/F440) was automatically calculated to obtain intracellular $\mathrm{pH}$. The measurements were unaffected by changes in the dye concentration (Thomas et al. 1979). A pair of measurements at 490 and $440 \mathrm{~nm}$ excitation was obtained every $10 \mathrm{msec}$. Fifty consecutive pairs of such measurements were averaged every $2.5 \mathrm{sec}$. The data were automatically acquired by the computer system and were analyzed later. The excitation light was shut off between measurements to minimize bleaching of the dye and possible cell damage.

Amiloride and atrial natriuretic polypeptide were obtained from Sigma Chemical Co. (St. Louis, MO, USA). UK-73967 was a gift from Pfizer Central Research, UK. All other chemicals were of reagent grade and were purchased from Wako Pure Chemicals (Osaka).

The data were analyzed using the paired $t$-test. Results were reported as means \pm s.E. Statistical significance was accepted for a $p$-value of less than 0.05 .

\section{RESUlts}

\section{In situ calibration of BCECF in proximal S2 tubule cells}

In the first series of experiments, BCECF trapped in the cells was calibrated intracellularly to correct for the influence of the intracellular environment on the properties of the dye. The calibration was performed in the perfusion chamber as in the experiments below. In order to correlate the fluorescence excitation ratios with cell $\mathrm{pH}$, the dye was calibrated intracellularly using nigericin (Thomas et al. 1979). The composition of the calibration solution was (in mmol/liter) $40 \mathrm{NaCl}$, $108 \mathrm{KCl}, 1.5 \mathrm{CaCl}_{2}, 1.0 \mathrm{MgCl}_{2}, 2 \mathrm{KH}_{2} \mathrm{PO}_{4}$, and $10 \mathrm{~N}$-2-hydroxethylpiperazine- $\mathrm{N}^{\prime}-$ 2-ethanesulfonic acid (HEPES), plus $5 \mu \mathrm{M}$ of nigericin. During the calibration procedure, the tubules were collapsed and the bath was perfused with the calibration solutions at different pHs. As in Fig. 1, the excitation ratio showed a clear correlation with the amibient $\mathrm{pH}$. The results of the calibration in 7 tubules are shown in Fig. 2. The excitation ratio varied from $1.37 \pm 0.02$ at $\mathrm{pH} 6.4$ to $3.35 \pm$ 0.05 at $\mathrm{pH} 7.9(n=7)$. 


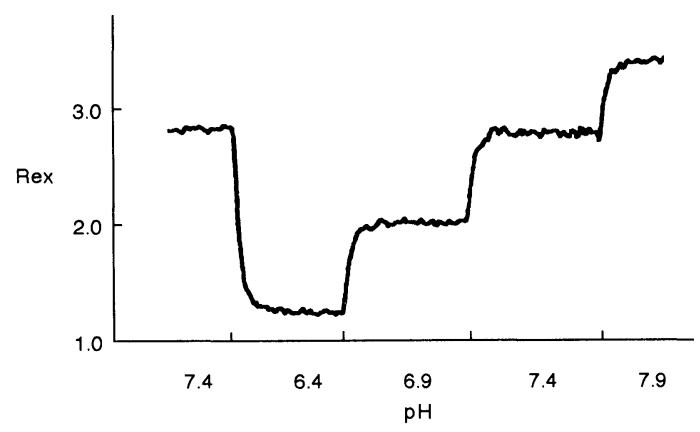

Fig. 1. In situ calibration of BCECF trapped in the proximal tubule cells.

The in situ calibration of BCECF was counducted by equilibrating intracellular $\mathrm{pH}$ with ambient $\mathrm{pH}$ using the nigericin-high potassium method (Thomas et al. 1979). First, the proximal tubule was incubated in normal solution containing $1 \mu \mathrm{M}$ BCECF / AM in the lumen. After BCECF/AM was washed out, the intracellular $\mathrm{pH}$ was equilibrated as described in the text. The intracellular $\mathrm{pH}$ was then calibrated by changing the ambient $\mathrm{pH}$ in a stepwise manner. Rex is excitation ratio.

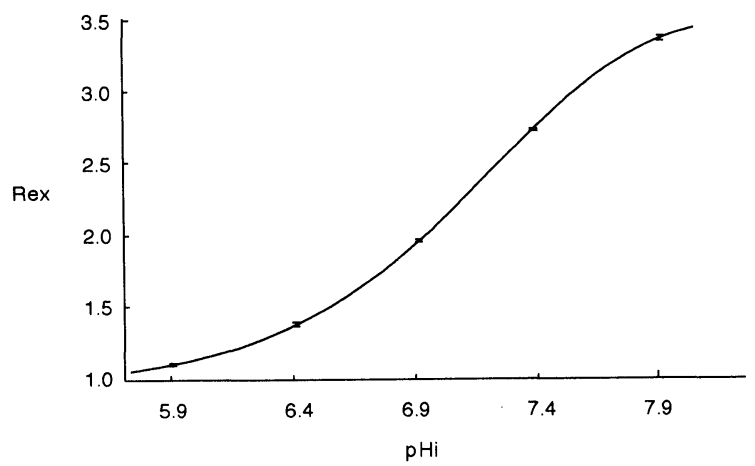

Fig. 2. Analysis of in situ calibration of BCECF trapped in 7 proximal tubules. The in situ calibration was conducted as described above. Rex was $1.12 \pm$ $0.03,1.37 \pm 0.02,1.96 \pm 0.02,2.78 \pm 0.02,3.35 \pm 0.05$ (mean \pm s.E.) when ambient $\mathrm{pH}$ was $5.9,6.4,6.9,7.4,7.9$, respectively.

\section{Validity of the preparation}

We measured luminal $\mathrm{pH}(\mathrm{pHl})$ by perfusing the lumen with control solution containing $10 \mu \mathrm{M}$ BCECF. Calibration of $\mathrm{pHl}$ was conducted in a glas pipette containing the same concentration of BCECF. $\mathrm{pHl}$ measured in three tubules was $7.39 \pm 0.02$. After clamping the distal end of the tubule $\mathrm{pHl}$ was gradually acidified and came to a steady-state of $6.61 \pm 0.07(n=3 . p<0.01)$ in several min. These results indicate that $\mathrm{HCO}_{3}$-reabsorption in this preparation is not damaged. Atriopeptidase activity in the in vitro preparation of proximal tubules is considered as Shima et al. reported (Shima et al. 1988). 


\section{Effect of API on $p H i$ of proximal S2 tubule}

After BCECF / AM was washed out of the lumen, $\mathrm{pHi}$ was measured intermittently as described above. Because the initial value of $\mathrm{pHi}$ tended to increase gradually, at least $5 \mathrm{~min}$ of equilibration was allowed before the measurements were started. In the initial steady state condition, the measured $\mathrm{pHi}$ varied from 6.92 to 7.26 , averaging $7.13 \pm 0.02$ in 19 tubules.

Then API at $10^{-8}$ to $10^{-4} \mathrm{~mol} /$ liter added to the bath solution of more than 10 min. The effect of API at $10^{-4} \mathrm{~mol} /$ liter in the bath is summarized in Fig. 3. API at $10^{-8}$ to $10^{-4} \mathrm{~mol} /$ liter in the bath showed virtually no effect on $\mathrm{pHi}$. These results show that API added to the bath has no effect on $\mathrm{pHi}$ for up to 10 $\min$.

Because API should inhibit the atriopeptidase that is located in the brush border membrane of the proximal tubule, we also applied API to the lumen and observed its effect on pHi after 10 min. The results are depicted in Fig. 4. As in the case of API applied to the bath, API applied to the lumen showed no effect on $\mathrm{pHi}$ at any concentration $\left(10^{-8}, 10^{-6}\right.$, or $\left.10^{-4} \mathrm{~mol} / \mathrm{liter}\right)$

The above data apparently indicate the lack of a direct effect of API on net buffer transport across both apical and basolateral membranes of proximal tubules. A synergistic change in the transport rate of $\mathrm{HCO}_{3}{ }^{-}$across the luminal and basolateral membranes would result in balanced stability of $\mathrm{pHi}$ in spite of a change in net transport. To overcome this effect, we conducted a series of experiments to identify the effect of API by modulating the synergistic change

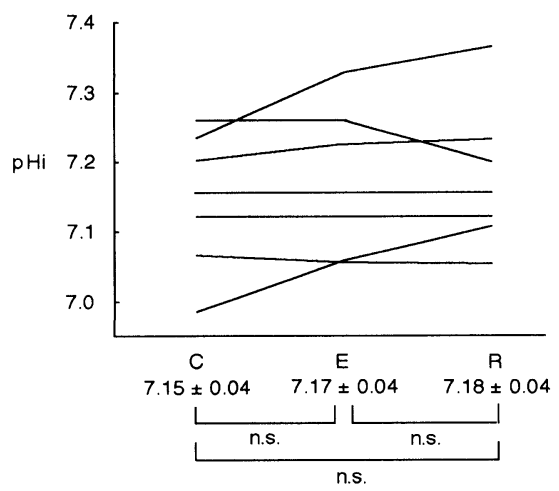

Fig. 3. Effect on pHi of atriopeptidase inhibitor (API) added to the peritubular solution. First, the proximal tubule was incubated with normal solution containing $1 \mu \mathrm{M} \mathrm{BCECF/AM} \mathrm{in} \mathrm{the} \mathrm{lumen.} \mathrm{After} \mathrm{BCECF/AM} \mathrm{was} \mathrm{washed}$ out, the measurements were started. After a control period of at least $10 \mathrm{~min}$, the peritubular solution was changed to one containing $100 \mu \mathrm{M}$ API. After 10 to $15 \mathrm{~min}$, the peritubular solution was changed to a control solution. The addition and removal of API did not change $\mathrm{pHi}$ in 7 proximal tubules. C, control period; E, experimental period; R, recovery period. 


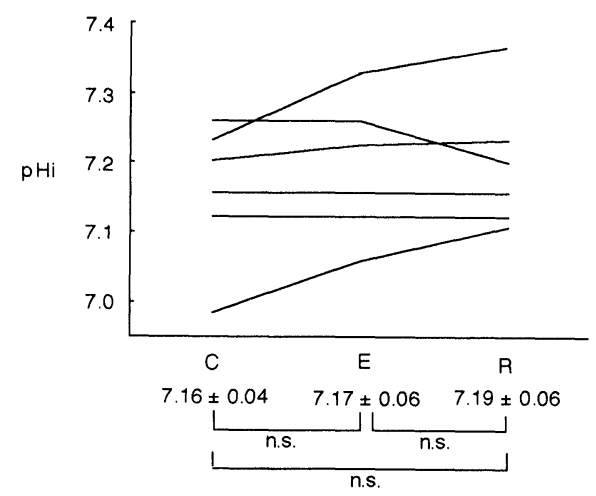

Fig. 4. Effect of API added to the luminal solution on pHi.

BCECF was loaded as described in Fig. 3. After a control period of more than $10 \mathrm{~min}, 100 \mu \mathrm{M}$ API was added to the lumen. After 10 to $15 \mathrm{~min}$, this was changed to a control solution. The addition and removal of API did not alter pHi $(n=6)$. C, control period; E, experimental period; $\mathrm{R}$, recovery period.

with a transport inhibitor which acts on only one side of the membrane. For this purpose, we chose amiloride as the inhibitor of the luminal $\mathrm{Na}^{+} / \mathrm{H}^{+}$antiporter. It is now well established that $\mathrm{HCO}_{3}{ }^{-}$reabsorption in the luminal membrane is mainly due to the $\mathrm{Na}^{+} / \mathrm{H}^{+}$antiporter. Therefore, the inhibition of this transporter by amiloride would allow the effect of API on pHi to be manifested, if the synergistic change was masking the effect of API in the proximal tubule. The results, shown in Fig. 5, clearly demonstrated that API had no effect on pHi even in the presence of luminal amiloride.

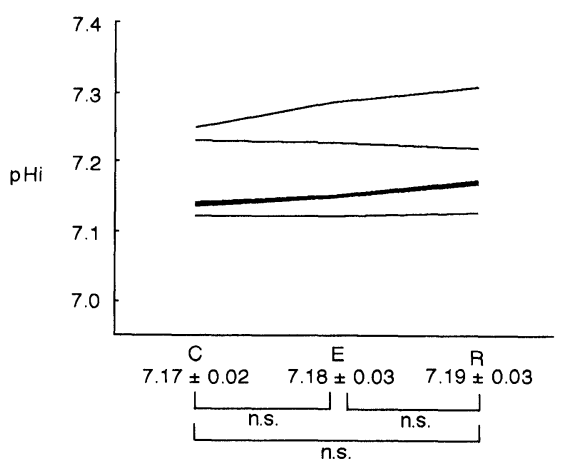

Fig. 5. Effect on pHi of API added to the peritubular solution in the presence of luminal amiloride. After the cells were loaded with BCECF, luminal perfusate was exchanged to a control solution containing $1 \mathrm{mM}$ amiloride. After 10 to 15 minutes, $100 \mu \mathrm{M}$ API was added to the peritubular solution. The addition and removal of API did not affect $\mathrm{pHi},(n=6)$. C, control period; $\mathrm{E}$, experimental period; $\mathrm{R}$, recovery period. 

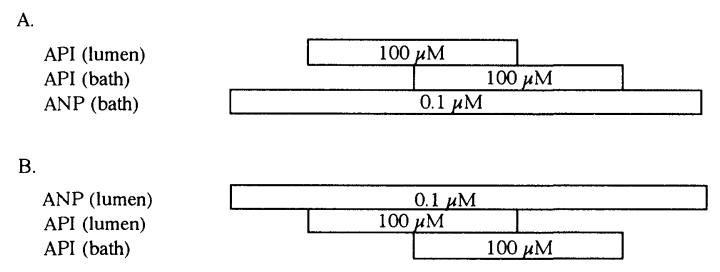

Fig. 6. Effect of ANP and interaction of ANP and API on pHi of proximal S2 tubule. A protocol shown in panel A was conducted to elucidate the effect of $100 \mu \mathrm{M}$ API on $\mathrm{pHi}$ in the presence of $0.1 \mu \mathrm{M}$ ANP in the peritubular solution. Panel B shows a protocol to examine the effect of $100 \mu \mathrm{M}$ API on pHi in the presence of $0.1 \mu \mathrm{M}$ ANP in the luminal solution.

Effect of $A N P$ and interaction of $A N P$ and $A P I$ on $p H i$ of proximal S2 tubule

To further examine the interaction of ANP and API, protocols as shown in Fig. 6 was conducted. Luminal and basolateral ANP was without effect on pHi. API added to either luminal or peritubular solution did not affect $\mathrm{pHi}$ in the presence of ANP on the basolateral or the luminal side of the membranes.

\section{Discussion}

Atrial natriuretic factor is widely recognized as a potent natriuretic substance that acts in fluid and electrolyte metabolism in the body. Although its effect on the kidney is still controversial, its importance in maintaining the circulatory volume has now been physiologically and pathophysiologically substantiated. Recently it has been reported that ANF is catabolized with the aid of atriopeptidase (AP), which is recognized as a specific peptidase. The distribution of AP was studied by Tang et al. and it is now clear that the most important part of the body for catabolizing ANP is the brush border membrane of the kidney (Olins et al. 1987). Because the half-life of ANP in the blood is extremely short (Yandle et al. 1986), AP should play an important role in maintaining the level of ANP. In this respect, inhibition of AP should cause an important change in the fluid and electrolyte balance.

In the present paper we utilized the newly-synthesized AP inhibitor, UK73967. In in vivo clearance studies, Candoxatril, a prodrug of UK-73967 clearly increased the serum level of ANP (Northridge et al. 1989) and caused significant natriuresis and diuresis. Except for its effect on the level of ANP in the blood, however, there have been no studies attempting to test whether this API excerts effects other than the inhibition of ANP catabolism. It is also unclear whether API changes the transport properties of the renal tubules. The aim of the present study was therefore to answer to such questions.

The measurement of $\mathrm{pHi}$ in detecting the effect of API is relevant at several 
points. In the proximal tubule, it is well established that the preferential $\mathrm{HCO}_{3}{ }^{-}$ reabsorption takes place. It is known that about two-thirds of the total fluid reabsorption is accompanied by $\mathrm{HCO}_{3}{ }^{-}$reabsorption. Intracellular $\mathrm{HCO}_{3}{ }^{-}$is known to be an important determinant of $\mathrm{pHi}$. The buffering capacity of proximal tubules in the presence of $\mathrm{HCO}_{3}{ }^{-}$is 2 times as high as that in the absence of $\mathrm{HCO}_{3}^{-}$(Preisig and Alpern 1988). This fact indicates that $\mathrm{pHi}$ in the presence of $\mathrm{HCO}_{3}{ }^{-}$primarily reflects the dynamics of $\mathrm{HCO}_{3}{ }^{-}$movement across the cell membranes of proximal tubule cells. Our study therefore represents an analysis of $\mathrm{HCO}_{3}^{-}$transport.

Recent studies have revealed the mechanism of $\mathrm{HCO}_{3}{ }^{-}$reabsorption across the proximal tubule cells. It is clear that $\mathrm{HCO}_{3}{ }^{-}$is reabsorbed across the brush border by the synergistic action of $\mathrm{Na}^{+} / \mathrm{H}^{+}$antiporter and the carbonic anhydrase, which allow $\mathrm{HCO}_{3}{ }^{-}$to permeate across the brush border in the form of lipidsoluble $\mathrm{CO}_{2}$ gas. The reabsorbed $\mathrm{CO}_{2}$ in turn is converted again to $\mathrm{HCO}_{3}{ }^{-}$and is taken out across the basolateral membrane by the rheogenic $\mathrm{Na}^{+}-\mathrm{HCO}_{3}{ }^{-}$ cotransporter and $\mathrm{Cl}^{-} / \mathrm{HCO}_{3}{ }^{-}$antiporter.

In the present study we found a lack of direct action of API on the proximal tubule. API may affect fluid and electrolyte transport via other transport mechanisms. The first candidate for such transport is $\mathrm{Cl}^{-}$, because one-third of the fluid transport is accompanied by $\mathrm{Cl}^{-}$(Rector 1983). Nevertheless, even in this case, the modulation of $\mathrm{Cl}^{-}$transport would change $\mathrm{pHi}$ due to the presence of $\mathrm{Cl}^{-} / \mathrm{HCO}_{3}^{-}$antiporter. We are therefore confident about the lack of a major direct effect of API on the proximal tubule.

We did not test the effect of API in other segments of the nephron. Recent studies using in vivo and in vitro microperfusion have provided abundant evidence for the effect of ANP on the collecting duct system (Dillingham and Anderson 1986; Zeidel et al. 1986, 1988; Nonoguchi et al. 1988, 1989; Rocha and Kudo 1990). It would be intriguing to test the effect of API in those segments. Furture studies are required to elucidate the comprehensive mechanism of the effect of API on the renal tubular system.

\section{Acknowledgments}

We thank Ms. C. Mezawa and Ms. C. Tanaka for their excellent technical support. We are also grateful to Profs. K. Yoshinaga, K. Tada, M. Imai, and Dr. Y. Imai, for their support and constructive criticism. This work was supported by a grant-in-aid from the Ministry of Education, Science and Culture, Japan.

\section{References}

1) Atlas, S.A., Kleinnert, H.D., Camargo, M.J., Januszewicz, A., Sealey, J.E., Laragh, J.H., Schilling, J.W., Lewicki, J.A., Johnson, L.K. \& Maack, T. (1984) Purification, sequencing and synthesis of natriuretic and vasoactive rat atrial peptide. Nature, 309, 717-719.

2) Borenstein, H.B., Cupples, W.A., Sonnenberg, H. \& Veress, A.T. (1983) The effect of 
the natriuretic atrial extract on renal haemodynamics and urinary excretion in anaesthetized rats. J. Physiol., 334, 133-140.

3) Burg, M., Grantham, J., Abramow, M. \& Orloff, J. (1966) Preparation and study of fragments of single rabbit nephrons. Am. J. Physiol., 210, 1293-1298.

4) Camargo, M.J.F., Kleinert, H.D., Atlas, S.A. \& Sealey, J.E. (1984) Ca-dependent hemodynamic and natriuretic effects of atrial extract in isolated rat kidney. $\mathrm{Am}$. J. Physiol., 246, F447-F438.

5) De Bold, A.J., Borenstein, H.B., Veress, A.T. \& Sonnenberg, H. (1981) A rapid and potent natriuretic response to intravenous injection of atrial myocardial extract in rats. Life Sci., 28, 89-94.

6) Dillingham, M.A. \& Anderson, R.J. (1986) Inhibition of vasopression action by atrial natriuretic factor. Science, 231, 1572-1573.

7) Flynn, T.G., De Bold, M.L. \& De Bold, A.J. (1983) The amino acid sequence of an atrial peptide with potent diuretic and natriuretic properties. Biochem. Biophys. Res. Commun., 117, 859-865.

8) Garvin, J.L. (1989) Inhibition of Jv by ANF in rat proximal straight tubules requires angiotensin. Am. J. Physiol., 257, F907-F911.

9) Gerves, A.L. \& Vollmar, A.M. (1990) Degradation and clearance of atrial natriuretic factors (ANF). Life Sci., 47, 1173-1180.

10) Harris, P.J., Thomas, D. \& Morgan, T.O. (1987) Atrial natriuretic peptide inhibits angiotensin-stimulated proximal sodium and water reabsorption. Nature, 326, 697698.

11) Kangawa, K., Tawaragi, Y., Oikawa, S., Mizuno, A., Sakuragawa, Y., Nakazato, H., Fukuda, A., Minamino, N. \& Matsuo, H. (1984) Identification of rat gamma atrial natriuretic polypeptide and characterization of the cDNA encoding-its precursor. Nature, 312, 152-155.

12) Kondo, Y. \& Froemter, E. (1987) Axial heterogeneity of sodium-bicarbonate cotransport in proximal straight tubule of rabbit kidney. Pfuegers Arch., 410, 481-486.

13) Kondo, Y., Imai, M., Kangawa, K. \& Matuo, H. (1986) Lack of direct action of $\alpha$-human atrial natriuretic polypeptide on the in vitro perfused segments of Henle's loop isolated from rabbit kidney. Pfluegers Arch., 406, 273-278.

14) Maki, M., Takayanagi, R., Misono, K.S., Pandey, K.N., Tibbetts, C. \& Inagami, T. (1984) Structure of rat atrial natriuretic factor precursor deduced from cDNA sequence. Nature, 309, 722-724.

15) Nonoguchi, H., Sands, J.M. \& Knepper, M.A. (1988) Atrial natriuretic factor inhibits vasopressin-stimulated osmotic water permeability in rat inner medullary collecting duct. J. Clin. Invest., 82, 1383-1390.

16) Nonoguchi, H., Sands, J.M. \& Knepper, M.A. (1989) ANF inhibits $\mathrm{NaCl}$ and fluid absorption in cortical collecting duct of rat kidney. Am. J. Physiol., 256, F179-F186.

17) Northridge, D.B., Jardine, A.G., Alabaster, C.T., Barclay, P.L., Connell, J.M. C., Dargie, H.J., Dilly, S.G., Findlay, I.N., Lever, A.F. \& Samels, G.M.R. (1989) Effects of UK69 578: A novel atriopeptidase inhibitor. Lancet, 2, 591-593.

18) Olins, G.M., Spear, K.L., Siegel, N.R. \& Zurcher-Neely, H.A. (1987) Inactivation of atrial natriuretic factor by the renal brush border. Biochem. Biophys. Acta, 901, 97100.

19) Preisig, P.A. \& Alpern, R.J. (1988) Chronic metabolic acidosis causes an adaptation in the apical membrane $\mathrm{Na} / \mathrm{H}$ antiporter and basolateral membrane $\mathrm{Na}\left(\mathrm{HCO}_{3}\right)$ symporter in the rat proximal convoluted tubule. J. Clin. Invest., 82, 1445-1453.

20) Rector, F.C., Jr. (1983) Sodium, bicarbonate, and chloride absorption by the proximal tubule. Am. J. Physiol., 244, F461-F472.

21) Richard, M., Espiner, E., Frampton, C., Ikram, H., Yandle, T., Sopwith, M. \& Cussans, N. (1990) Inhibition of endopeptidase EC 24.11 in humans. Hypertension, 16, 269276. 
22) Rocha, A.S. \& Kudo, L.H. (1990) Atrial peptide and cGMP effects on $\mathrm{NaCl}$ transport in inner medullary collecting duct. Am. J. Physiol., 259, F258-F268.

23) Shima, M., Seino, Y., Torikai, S. \& Imai, M. (1988) Intrarenal localization of degradation of atrial natriuretic peptide in isolated glomeruli and cortical nephron segments. Life Sci., 43, 357-363.

24) Takezawa, K., Cowley, A.W., Jr., Skelton, M. \& Rpman, R.J. (1987) Atriopeptin III alters renal medullary hemodynamics and the pressure-diuresis response in rats. $\mathrm{Am}$. J. Physiol., 252, F992-F1002.

25) Thomas, J.A., Buchsbaum, R.N., Zimnick, A. \& Rache, F. (1979) Intracellular pH measurement in Ehrlich ascites tumor cells utilizing spectroscopic probes generated in situ. Biochemistry, 18, 2210-2218.

26) Winaver, J., Burnett, J.C., Tyce, G.H. \& Dousa, T.P. (1990) ANP inhibits $\mathrm{Na}^{+}-\mathrm{H}^{+}$ antiport in proximal tubular brush border membrane: Role of dopamine. Kidney Int., 38, 1133-1140.

27) Yamanaka, M., Greenberg, B., Johnson, L., Seilhammer, J., Brewer, M., Friedmann, T., Miller, J., Atlas, S., Laragh, J., Lewicki, J. \& Fiddes, J. (1984) Cloning and sequence analysis of the cDNA of the rat atrial natriuretic factor precursor. Nature, 309, 719722.

28) Yandle, T.G., Richard, M.G., Nicholls, M.G., Cuneo, R., Espiner, E.A. \& Livesey, J.H. (1986) Metabolic clearance rate and plasma half life of alpha-human atrial natriuretic peptide in man. Life Sci., 38, 1827-1833.

29) Zeidel, M.L., Seifter, J.L., Lear, S., Brenner, B.M. \& Silva, P. (1986) Atrial peptides inhibit oxygen consumption in kidney medullary collecting duct cells. $A m$. J. Physiol., 251, F379-F383.

30) Zeidel, M.L., Kikeri, D., Silva, P., Burrowes, M. \& Brenner, B.M. (1988) Atrial natriuretic peptides inhibit conductive sodium uptake by rabbit inner medullary collecting duct cell. J. Clin. Invest., 82, 1067-1074. 